Курбанов Р.A.

\title{
РЕГИОНАЛЬНАЯ ИНТЕГРАЦИЯ В АФРИКЕ: МЕЖАФРИКАНСКАЯ КОНФЕРЕНЦИЯ РЫНКОВ СТРАХОВАНИЯ
}

Аннотация: В данной статье рассматривается функиионирование; институииональная структура ; деятельность и основные виды нормативных актов Межафриканской организации рынков страхования. Рассматривается взаимодействие данной организации с национальными страховыми организациями африканских государств-членов, а также исследуется влияние ее деятельности на законодательство государств-членов. Автор отмечает, что данная организация является наднациональной региональной организаџией, так как глубоко интегрирует законодательства государств-членов с надначиональным правом, разрабатываемым данной организачией. Действительно, как отмечает автор, здесь существует требование о гармонизации законодательств государствчленов, а также возможность принятия отдельных решений органов власти организачии на основе (квалифицированного) большинства; более того, здесь существует общее законодательство - Кодекс страхования и даже вторичное право. В статье обращается внимание на то, что глубокие интеграционные процессы, которые мы можем наблюдать в рамках данной организации, ограничиваются лишь отдельной сферой правового сотрудничества государств-членов - страхового дела. Иначе говоря, данная организачия является узкопрофильной. Как следствие, вторичное право здесь скудно, а институциональная организация остается рудиментарной.

Ключевые слова: Регионализация, интеграция, гармонизачия законодательства, унификация законодательства, страхование, межафриканская конференция, институциональная структура, государства-участники, интеграиионные процессы, учредительный договор.

Abstract: This article examines the functionality, institutional structure, work and main types of normative acts of CIMA. The author reviews the correlation between this organization and national insurance organizations of the African memberstates, as wells as analyzes the impact of its work upon the legislation of the member-states. The author notes that this organization is a supranational regional organization, as it deeply integrates the legislation of the member-states with the supranational law developed by this organization. The article highlights the fact that the deep integrational processes that we can observe within the framework of this organization are limited only by a separate sphere of legislative cooperation between the member-states - the insurance industry.

Keywords: Inter-African Conference, insurance, unification of legislation, harmonization of legislation, integration, regionalisation, institutional structure, member states, integration processe, treaty.

\section{Цели и история создания}

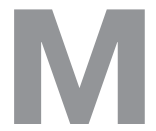
ежафриканская конференция рынков страхования является межгосударственной организацией, в сферу деятельности которой входит регулирование рыков страхования ее государств-членов. Предшественницей данной организации была Международная конференция по управлению рынками страхования (Conférence Internationale des Contrôles d'Assurances (CICA)), которая была создана 17 июля 1962 г. в Париже в результате подписания соответствующего соглашения Францией, с одной сто- роны, и четырнадцатью африканскими государствами (а также Мадагаскаром), с другой стороны. 10 июля 1992 г. с подписанием договора в г. Яунде (Камерун) CICA была преобразована в Межафриканскую конференцию рынков страхования (СIMА). Данный договор стал учредительным актом новой межгосударственной организации страхового дела.

Правительства Республики Бенин, Буркина Фасо, Республики Камерун, Центральноафриканской Республики, Республики Конго, Республики Кот-д’Ивуара, Габонской Республики, Республики Мали, Республики Нигер, Республики Сенегал, Ре- 
DOI: $10.7256 / 1811-9018.2015 .4 .14841$

При цитировании этой статьи сноска на dоі обязательна

\section{Право и политика 4 (184) 2015}

спублики Чад, Тоголезской Республики стали учредителями новой организации.

Статья 1 Яундского договора, определила цели организации:

- принятие всех мер, необходимых для усиления и консолидации сотрудничества в области страхования, чтобы рынки стран-участниц стали более адаптированными к африканским реалиям и учитывали финансовые возможности участников этих рынков. Речь, в частности, идет о рисках аграрного и сельскохозяйственного секторов, а также рисках, связанных с внешней торговлей;

- направленность деятельности Конференции на стимулирование внедрения всех необходимых инструментов льготного страхования, позволяющих организациям страхования и/или перестрахования, действующим в странах, в которых намечается рост случаев задержки с выплатой взносов на уровне отдельных государств и региона в целом, осуществлять свою деятельность при помощи адекватных технологий. В том числе при помощи страхования и управления крупными рисками, размеры которых превосходят способности страховых рынков отдельных государств;

- разработка необходимой нормативной базы, обеспечивающей стимулирование инвестиционной деятельности на местах, создание наиболее благоприятных условий для экономик стран-участниц и региона в целом, позволяющей генерировать технические и финансовые резервы за счет операций страхования и перестрахования;

- проведение политики в сфере профессиональной подготовки управленческих и технических кадров в сфере страхования, отвечающей потребностям страховых предприятий и органов управления государств-участников;

- рационализация управления кадровыми и техническими ресурсами таких предприятий и органов путем специализации и непрерывного повышения и квалификации;

- создание совместных структур, уполномоченных на проведение анализа и внедрение стратегии и политических решений в выше названных вопросах, с целью: облегчения условий создания здорового и сбалансированного развития страховых компаний; способствования образованию на общем пространстве стран-участниц более обширного и интегрированного рынка, обеспечивающего условия достаточной устойчивости с технической, экономической и финансовой точек зрения; внедрения новых финансовых инструментов для обеспечения высокой доходности инвестиций компаний, занимающихся страхованием и перестрахованием, и других инвесторов. Данная цель должна обеспечиваться, в том числе, за счет создания в монетарных зонах государств-членов соответствующих финансовых рынков и инструментов.

- проведение политики гармонизации и унификации законодательства и подзаконных актов, регулирующих операции по страхованию и перестрахованию, а также касающиеся контроля за организациями страхования и перестрахования, действующими на территории стран-участниц. Гармонизация законодательств касается также и всех других целей, которые по своей природе должны содействовать развитию страхового дела, развитию инструментов управления и предотвращения страховых рисков в государствах-участниках;

- обеспечение финансовыми, материальными и кадровыми ресурсами общих институтов межправительственной организации, которые страны-участницы должны создать с целью развития кооперации в вопросах страхования и перестрахования.

\section{Институциональная структура организации}

Некоторые институциональные органы Конференции были созданы еще до подписания договора в г. Яунде, то есть еще в период деятельности Международной конференции по управлению рынками страхования - это Международный институт страхования и Объединенная компания по перестрахованию государств-участников СІСА, однако в дальнейшем эти организации были реорганизованы.

В соответствии с договором Яунде в настоящее время функционируют:

- Совет министров Конференции;

- Региональная комиссия по контролю за сектором страхования;

- Генеральный секретариат Конференции.

Конференция является юридическим лицом, а учреждения (институты) организации являются самостоятельными юридическими лицами (ст. 58). Конференция и институты пользуются на территориях государств-участников правами, иммунитетами и привилегиями, которыми обычно наделяется любая международная организация. Представительства организации могут учреждаться в столицах государств-участников, подписавших договор. 


\section{Совет министров}

В соответствии со ст. 6 договора Совет министров является руководящим органом Конференции и обеспечивает реализацию целей учредительного договора:

- $\quad$ разрабатывает и принимает единое страховое законодательство для всех государств-участников. В целях осуществления этой миссии он изменяет и дополняет в порядке регламентирования единый страховой кодекс, прилагаемый к учредительному договору;

- $\quad$ определяет политику Конференции в вопросах профессионального образования в страховом секторе;

- следит за соблюдением государствами-участниками единого законодательства и за исполнением ими обязательств, вытекающих из учредительного договора. В рамках выполнения данной задачи Совет путем издания распоряжений уточняет действие обязательств, соблюдение которых ложится на государства-участники; по инициативе последних он принимает рекомендации, касающиеся любого вопроса по функционированию сектора страхования государств-членов;

- является единственной апелляционной инстанцией для обжалования дисциплинарных санкций, выносимых Региональной комиссией по контролю за сектором страхования;

- утверждает свой внутренний регламент, уставы органов Конференции и специализированных учреждений (институтов), а также статус сотрудников органов Конференции;

- принимает внутренний регламент Экспертного комитета.

\section{Состав Совета министров}

Совет состоит из отраслевых министров государствчленов, курирующих сектор страховых услуг. Каждое государство-участник представлено в Совете одним представителем (ст.8). Председательство в Совете осуществляется его членами по очереди (на ротационной основе), на срок в один год каждым из членов Совета (ст.10). Совет собирается один раз в год на очередные заседания, приуроченные к встречам министров Зоны франка. Внеочередные заседания Совета созывает его председатель, действуя по собственной инициативе или по просьбе как минимум двух членов Совета.

В промежутках между заседаниями Совета письменная процедура принятия решения может применяться либо по инициативе самого Совета, либо по просьбе как минимум двух государств-участников организации. Письменная процедура не может применяться для принятия или изменения единого страхового законодательства, для обжалования решений Ко- миссии, а также в порядке применения положений ст. 7 учредительного договора (ст.11). Повестка дня заседаний Совета утверждается его председателем с учетом предложений, поступивших от государств-участников. В повестку дня Совета обязательно входит изучение предложений и мнений, поступивших от Генерального секретаря Конференции.

\section{Порядок принятия решений}

Решения Совета принимаются присутствующими членами или представителями на единогласной основе (ст.13). Если по одному или нескольким пунктам повестки дня заседаний Совета единогласного решения присутствующих членов или представителей не достигнуто, обсуждение таких вопросов возобновляется на следующем заседании, причем решения по ним принимается уже квалифицированным большинством в две трети голосов.

В рамках предварительного рассмотрения предложений и материалов, представленных в Совет государствами, генеральный секретарь Конференции (организации) принимает техническое решение, основанное на заключении Комитета экспертов, в задачи которого, помимо прочего, входит подготовка рабочих документов Совета и составление заключений. Каждый член Совета назначает от своей страны эксперта по страховому сектору для участия в работе Комитета экспертов. В данный Комитет входят также генеральный директор Международного института страхования (IIA), генеральный директор CICA-RE (Объединенной компании по услугам перестрахования государств-участников Межафриканской Конференции рынков страхования) и два представителя FANAF (Федерации африканских национальных страховых обществ - La Fédération des Sociétés d'Assurances de Droit National Africaines).

На основании обращения Комиссии или генерального секретаря Совет может констатировать, что то или иное государство-участник не выполняет обязательства, взятые на себя по данному договору. В таком случае Совет направляет соответствующему государству предупреждение о необходимости принять все необходимые меры для упорядочения отношений с организацией (ст.46).

Юридическая сила актов, изданных органами Конференции, может быть оспорена в Совете путем подачи иска в течение двух месяцев после их опубликования или нотификации (ст. 48).

Совет принимает решения относительно толкования учредительного договора и актов, изданных органами Конференции (организации), по запросу государства-участника или по своей инициативе в случаях, 
DOI: $10.7256 / 1811-9018.2015 .4 .14841$

При цитировании этой статьи сноска на dоі обязательна

\section{Право и политика 4 (184) 2015}

когда интерпретационные расхождения в решениях национальных арбитражных органов могут стать препятствием для единообразного применения права Конференции. Толкования права организации, принятые Советом, обязательны для всех административных и судебных национальных органов власти (ст. 49).

Региональная комиссия по контролю за сектором страхования

Региональная комиссия по контролю за сектором страхования является регулирующим органом Конференции. Она уполномочена осуществлять контроль за страховыми компаниями; обеспечивать общее наблюдение и содействовать национальным рынкам страхования. В рамках своей контрольной миссии Комиссия организует контроль за документооборотом и контроль страховых компаний, действующих на территории стран-участниц, на местах (ст. 17). Для осуществления этих задач Комиссия располагает штатом контролеров, образованным внутри Генерального секретариата Конференции. Национальные дирекции, отвечающие за контроль страховых компаний, направляют в Комиссию свои отчеты, подготовленные в рамках исполнения ими их собственных полномочий, а также любую другую информацию, необходимую для осуществления контрольных мероприятий Комиссии. В условиях, определенных единым страховым законодательством, контроль на местах может быть распространен на материнские компании, на филиалы контролируемых страховых обществ, а также на любую посредническую или экспертную фирму.

Когда в отношении страхователей делается вывод о несоблюдении ими договорных обязательств, Комиссия обязует страховую компанию принять меры по исправлению ситуации, указывая при этом, какие конкретно меры ей следует принять. Если Комиссия констатирует нарушение правил страхования со стороны какой-либо контролируемой компании, она применяет следующие дисциплинарные санкции:

- предупреждение;

- порицание;

- $\quad$ ограничение или запрет на все или часть операций;

- прочие ограничения на осуществление профессиональной деятельности;

- $\quad$ временное отстранение от работы или увольнение руководителей;

- отзыв лицензии на осуществление страховой деятельности.

Помимо прочего Комиссия имеет право налагать штрафы и предписывать принудительную передачу портфеля страховых контрактов. Данные компетен- ции свидетельствуют о том, что организация обладает элементами наднациональности. Тем не менее, их действие ограничено исключительно сферой деятельности страховых компаний и не носит общего характера.

В рамках своей миссии по наблюдению и организационной деятельности, Комиссия:

- дает заключение, которое является условием для выдачи профильным министром того или иного государства разрешения (лицензии) на осуществление страховой деятельности;

- запрашивает все документы и статистические материалы, касающиеся национальных рынков страхования стран-участниц;

- направляет в Совет Конференции свои выводы и предложения относительно функционирования сектора страхования, а также предлагает проекты по изменению учредительного договора и единого законодательства, которые ему представляются целесообразными ;

- направляет в органы власти государств-участников свои выводы, касающиеся того, как выполняются решения Комиссии на территории этих государств, а также направляет свои рекомендации относительно функционирования национальных рынков страховых услуг.

Генеральный Секретариат Конференциии

Внутри организации существует отдельная структура - Генеральный Секретариат Конференции, в задачи которого входит содействие достижению целей CIMA (ст. 31). Для достижения данных целей Генеральный Секретариат Конференции:

- обеспечивает подготовку, исполнение и сопровождение работы Совета и Комиссии;

- представляет в Совет, если считает необходимым, любые предложения по внесению изменений и дополнений в единое законодательство, и формулирует свои заключения касательно реализации целей настоящего договора;

- утверждает регламенты по имплементации актов, изданных Советом;

- осуществляет, по своей инициативе или на основании инструкций Комиссии, контроль страховых компаний, аккредитованных на территории государствучастников;

- передает в Совет материалы, представленные генеральным директором Международного Института страхования (IIA) и генеральным директором Объединенной компании по услугам перестрахования государств-участников Межафриканской Конференции рынков страхования (CICA-RE); 
- представляет в Совет ежегодный отчет о выполнении своих задач, о деятельности Совета и о ситуации в секторе страховых услуг.

Генеральный секретарь назначается Советом на пятилетний срок с правом переназначения на еще один срок. Кандидат на должность должен подтвердить свои специальные знания и иметь опыт работы в области страховых услуг. Совет может в любой момент приостановить действие мандата генерального секретаря (ст. 32). Совет назначает двух заместителей генерального секретаря (ст. 36). Генеральный секретарь представляет в Совет проекты по применению регламентов (ст. 31). Окончательное принятие регламентов возможно только по истечении трех месяцев с момента их представления в Совет (ст. 34).

\section{Основные правовые акты организации}

Кодекс страховой деятельности [1] (Code de la Conférence Interafricaine des Marchés d'Assurance)

Соглашение, заключенное в г. Яунде, является основополагающим (учредительным) актом организации. Кодекс страховой деятельности, фигурирующий в приложении 1 Соглашения, устанавливает единое страховое законодательство.

Данный кодекс формирует единый для странучастниц свод норм, который начиная с 15 февраля 1995 г. заменил для африканских государств зоны франка аналогичные национальные нормативные акты. Кодекс состоит из шести частей.

Часть I кодекса СIMA

Эта часть кодекса посвящена страховому договору, в некотором смысле она представляет собой переработанный, актуализированный и усовершенствованный французский закон от 13 июля 1930 г., который до последнего времени регулировал страховые договоры в Кот-д’Ивуаре и в государствах зоны франка. Цель, которую преследовали составители при редактировании данной части кодекса, состоит в упрощении текстов норм и, в частности, в повышении их ясности и прозрачности.

В соответствии с обновленным кодексом договоры страхования жизни содержат ряд новшеств. Так, в частности, в обязанности страховщика вменяется возврат сумм, внесенных по просьбе страхователя, по истечении двух лет выплаты взносов, а не трех лет, как было первоначально. Кроме того, страховые компании обязуются более полно информировать застрахованных лиц относительно всех элементов договора страхования (размер суммы, вносимой страховщиком по просьбе страхователя; размер скидок; размер авансовых платежей). Данной частью кодекса также устанавливаются:

размер штрафа за просрочку выплат, который не может превышать 5\% от всего объема выплат;

участие застрахованного лица в прибыли, получаемой страховщиком;

прозрачные правила для групповых контрактов.

Часть II кодекса CIMA

Эта часть кодекса посвящена нормам обязательного страхования, в том числе обязательного страхования автогражданской ответственности [2]. Положения Части II вводят шкалу компенсационных выплат и позволяют большему числу пострадавших (жертв) получить страховые выплаты. Так, помимо прочего, компенсационные выплаты распространяются как на членов семей застрахованных лиц, так и на третьих лиц, чего не было в прежнем законе.

Помимо прочего часть вторая кодекса устанавливает положения о:

- франшизе (освобождении от выплаты взносов);

- страховых выплатах в случае вождения автомобиля в состоянии алкогольного опьянения;

- лишении застрахованного лица права на страховое возмещение (вне случаев законной приостановки действия страховых гарантий в случае неуплаты страховых взносов);

- форс-мажоре, действиях третьих лиц и вине потерпевшего (за исключением правонарушений, совершенных водителями, а также возможного ущерба, который могут причинить наемные работники страхователя при исполнении своей работы).

Часть III кодекса СIMA

В данной части кодекса содержаться правила выдачи лицензии стразовым компания на осуществление страховой деятельности. Здесь в частности устанавливаются требования к уровню платёжеспособности стразовых компаний; принципы, касающиеся инвестиций, осуществляемых страховыми компаниями; процедуры выдачи лицензий на осуществление страховой деятельности и т.п.

Часть IV кодекса CIMA

Эта часть кодекса содержит план бухгалтерской отчетности страховых компаний, где содержаться образцы документов, предназначенные для проведения контроля за деятельностью страховых компаний государств CIMA.

Часть Vкодекса CIMA

Эта часть регламентирует деятельность посредников при оказании страховых услуг (куртье, посредники с широкими полномочиями и другие). Здесь в качестве 
DOI: $10.7256 / 1811-9018.2015 .4 .14841$

При цитировании этой статьи сноска на dоі обязательна

\section{Право и политика 4 (184) 2015}

условий допуска к деятельности определены такие критерии как финансовая репутация, профессионализм, а также наличие финансовых гарантий.

\section{Часть VI кодекса CIMA}

В части VI говорится об учреждении Фонда автогражданской ответственности в каждом государствеучастнике. Этот фонд, после своего создания, уполномочен возмещать убытки лицам, пострадавшим в ДТП в случаях, когда виновный в происшествии не установлен либо не застрахован.

\section{Вторичное право организации [3]}

В ст. 36 Яундского соглашения говорится: «Для выполнения своих задач на условиях, предусмотренных настоящим договором, органы Конференции принимают:

- регламенты и решения;

- дают рекомендации и высказывают мнения.

Таким образом, вторичное право организации (Конференции) состоит из:

- Регламентов и решений, принимаемых органами Конференции

- Рекомендаций и мнений органов Конференции

Регламентарные акты и решения органов Конференции обязательны для выполнения. Регламентарные акты имеют общее значение и применяются напрямую во всех государствах-участниках, что свидетельствует о наличии зачатков наднациональности в рамках рассматриваемой организации. В свою очередь, рекомендации и мнения не являются обязательными для выполнения. Регламентарные нормы публикуются в Официальном бюллетене Конференции (ст. 39). Правовое и материальное исполнение актов, принятых органами Конференции, обеспечивается государствами-участниками.

\section{Функционирование организации}

\section{Бюджет организацุии}

На основании предложения генерального секретаря, после ознакомления с заключением экспертного комитета и до открытия финансового года, Совет утверждает бюджет Конференции (ст.50).

Доходные статьи бюджета органов Конференции включают ежегодные взносы, перечисляемые государствами-участниками; финансовую помощь, субвенции, которые могут поступать от любого государства-участника, любого третьего государства или от любой организации; заимствования по договору, осуществляемые с целью исполнения инвестиционных расходов и про- чие поступления. За исполнение бюджета Конференции отвечает Генеральный секретарь.

Совет утверждает бюджет Международного Института Страхования (IIA) на условиях, предусмотренных уставом и финансовым регламентом последнего (ст. 54).

До окончания каждого календарного года Совет утверждает размер взносов, необходимых для обеспечения работы органов Конференции и IIA. Министры государств-участников, курирующие сектор страховых услуг, уведомляют страховые компании до 31 марта каждого года о размерах причитающихся с них взносов за текущий год, выделяя доли, предназначенные для органов Конференции, для IIA и для обеспечения деятельности национальных органов управления рынком страхования.

Одновременно с этим министр каждого государства-участника, курирующий рынок страхования, информирует генерального секретаря Конференции и генерального директора IIA о требованиях по возмещению неоплаченной части взносов в бюджеты Конференции и IIA, которые направляются в адрес каждой страховой компании.

На основании предложений генерального секретаря, Совет утверждает финансовый регламент, детально оговаривающий способы и порядок составления и исполнения бюджета Конференции, представления отчетов о расходовании средств и проверок бухгалтерской документации (ст.57). На основании предложений генерального директора IIA, Совет утверждает способы и порядок составления и исполнения бюджета Организации, представления отчетов о расходовании средств и проверок ее бухгалтерской документации.

Бухгалтер-ревизор, назначаемый Советом на пять лет с правом одноразового переназначения, утверждает точность и законность бухгалтерских отчетов, представленных генеральным секретарем Конференции и генеральным директором IIA. Бухгалтер-ревизор действует в соответствии с общими или частными директивами Совета и: - $\quad$ самостоятельно определяет срок и порядок проведения проверок;

- $\quad$ представляет свой доклад с результатами проверки отчетов генеральному секретарю Конференции и генеральному директору IIA в течение двух месяцев после окончания финансового года.

После получения докладов бухгалтера-ревизора генеральный секретарь Конференции и генеральный директор IIA передают их каждому государству-участнику и обращаются к административным и финансовым ревизионным комиссиям, указанным во внутреннем регламенте экспертного комитета, с предложением ознакомиться с докладом и сформулировать соответствующие рекомен- 
дации. Генеральный секретарь Конференции и генеральный директор IIA представляют Совету доклады бухгалтера-ревизора и доклады ревизионных комиссий.

Порядок вынесения санкиий Комиссией по контролю за рынком страхования [4]

Как мы уже отметили, Региональная комиссия уполномочена осуществлять контроль страховых компаний она обеспечивает общее наблюдение за национальными рынками страхования и способствует их формированию и развитию. Комиссия наделена правом налагать санкции в отношении страховых и перестраховочных компаний, действующих на территории государств-участников. Такие решения (о санкциях) должны быть мотивированы. Санкции могут быть вынесены только после того, как должностные лица конкретной компании, которые могут прибегнуть к услугам представителя своей Профессиональной Ассоциации, представят свои разьяснения в письменной форме или путем собеседования. Санкции должны быть исполнены после соответствующего уведомления заинтересованных лиц.

В том, что касается отзыва лицензии, или разрешения (на занятие страховой деятельностью), необходимо отметить, что данная мера вступает в силу только по истечении месяца после уведомления о принятом решении министра, курирующего страховой сектор. Эта отсрочка предусмотрена на случай обжалования санкций в Совете, в соответствии с процедурой, предусмотренной ст. 22 Яундского договора. Для исполнения санкций, предусмотренных ст. 17, Комиссия в случае необходимости предлагает министру соответствующего государства, курирующему сектор страховых услуг, назначить временного администратора. Когда для исполнения решений Комиссии необходимо назначить ликвидатора, она направляет соответствующее ходатайство в профильный судебный орган и информирует об этом министра соответствующего государства, отвечающего за сектор страховых услуг. Осуществление контрольных мероприятий на месте и применение санкций, указанных в ст. 17, предполагает право их оспаривания в порядке, определенном единым страховым законодательством (ст.18).

Предписания и санкции, вынесенные Комиссией, принимают форму решений (ст.19). О решениях и предупреждениях Контрольной комиссии ставятся в известность заинтересованные предприятия и министр, курирующий страховой сектор соответствующего государства-участника. Решения подлежат исполнению сразу после их нотификации (ст. 21). Решения Комиссии могут быть обжалованы только в Совете и только в течение двух месяцев после их нотификации.
Совет имеет право отменять решения Комиссии. Решения принимаются Комиссией по результатам обсуждения, простым большинством голосов присутствующих членов или их представителей. При равенстве голосов голос Председателя является решающим.

\section{Национальные дирекции по управлению рынками страхования [3]}

\section{Общие полномочия}

Национальные дирекции по управлению рынками страхования, созданные государствами-участниками, служат посредниками в деятельности Комиссии Конференции (организации) на территории государствучастников. В частности, они обеспечивают на территории государств-участников:

- развитие сектора страховых услуг;

- соблюдение интересов страхователей и застрахованных лиц по договорам страхования и договорам капитализации процентов (contrats de capitalisation);

- защиту средств, накопленных компаниями для возмещения расходов (технических резервов);

- оказывают экспертную и консультационную помощь по вопросам страхования органам государственной власти;

- осуществляют общее наблюдение за рынком страховых услуг.

Дирекции предоставляют Комиссии все сведения о состоянии компаний и развитии страхового рынка того или иного государства, чтобы Комиссия могла своевременно принять необходимые решения.

\section{Специальные полномочия}

Национальные дирекции по управлению рынками страхования обеспечивают соблюдение нормативных актов организации; единого законодательства; осуществляют контроль за соблюдением учредительного договора.

- дирекции могут также следить за спорами, которые возникают на рынке страховых услуг, между страховщиками, с одной стороны, и застрахованными лицами, с другой стороны;

- дирекции сообщают Комиссии о результатах осуществляемых ими контрольных мероприятий;

- дирекции осуществляют сбор необходимых данных: статистики, балансов, аналитики, результатов проверок;

- дирекции осуществляют предварительное рассмотрение заявок на получение разрешений (лицензий) на осуществление страховой деятельности;

- дирекции могут вести дела, связанные со страховыми договорами, и следить за надлежащей редакцией содержания таких договоров; 
DOI: $10.7256 / 1811-9018.2015 .4 .14841$

При цитировании этой статьи сноска на dоі обязательна

\section{Право и политика 4 (184) • 2015}

- дирекции выдают разрешение на занятие страховой посреднической деятельностью и следят за соблюдением требований профессиональной квалификации и платежеспособности, которые предъявляются к этой профессии;

- дирекции осуществляют контроль за деятельностью технических экспертов, которые помогают оценить убытки по страховым случаям и содействуют надлежащему исполнению договоров страхования.

Конференция рекомендовала государствам-участникам определить в разумные сроки специальный статус страховых инспекторов и контролеров, полномочия которых перечислены выше.

$* * *$

На первый взгляд, Межафриканская конференция рынков страхования является глубоко интегрирован- ной, наднациональной организацией. Действительно, здесь существует требование о гармонизации законодательств государств-членов, а также возможность принятия отдельных решений органов власти организации на основе (квалифицированного) большинства. Более того, здесь существует общее законодательство - Кодекс страхования и даже вторичное право.

Тем не менее стоит отметить, что настолько глубокие интеграционные процессы, которые можно наблюдать в рамках данной организации, ограничиваются лишь отдельной сферой правового сотрудничества страхованием. Иначе говоря, данная организация является узкопрофильной. Как следствие, вторичное право здесь скудно, а институциональная организация остается рудиментарной.

\section{Библиография:}

1. D. Ndoye, Code CIMA: l'assurance dans les pays membres de la CIMA : les textes annotés, Éditions juridiques africaines, 2007

2. P. Diouf, Le fonds de garantie automobile sénégalais et l'indemnisation des préjudices corporels consécutifs aux accidents de la circulation, These, $2000-828$

3. Z. Yigbedek, L'interprétation des dispositions du Code CIMA sur contrat d'assurance, Presses Universitaires de Yaoundé, 2003

4. S. Michaïlof, La France et l'Afrique: vade-mecum pour un nouveau voyage, KARTHALA Editions, 1993-p. 413

5. Курбанов Р.А. Региональная интеграция в Африке: Межафриканская конференция социального страхования // Право и политика. - 2015. - 3. - С. 319 - 326. DOI: 10.7256/1811-9018.2015.4.14689.

6. Рогов И.И. Принцип верховенства конституции как ключевой фактор развития межгосударственных интеграционных процессов // Журнал зарубежного законодательства и сравнительного правоведения / Journal of foreighn legislation and comparative law. - 2013. - 6. - С. $964-966$.

7. Курбанов Р.А. Структура энергетического сектора и вопросы международно-правового регулирования энергетики Североамериканских государств // Международное право. - 2013. - 4. - C. 201 - 228. DOI: 10.7256/2306-9899.2013.4.11026. URL: http://www.e-notabene.ru/wl/article_11026.html

8. Курбанов Р.А. Евразийское право: вопросы концептуального развития // Право и политика. - 2014. - 12. - С. 1877 - 1887. DOI: $10.7256 / 1811-9018.2014 .12 .14003$.

\section{References (transliterated):}

1. D. Ndoye, Code CIMA: l'assurance dans les pays membres de la CIMA : les textes annotés, Éditions juridiques africaines, 2007

2. P. Diouf, Le fonds de garantie automobile sénégalais et l'indemnisation des préjudices corporels consécutifs aux accidents de la circulation, These, $2000-828$

3. Z. Yigbedek, L'interprétation des dispositions du Code CIMA sur contrat d'assurance, Presses Universitaires de Yaoundé, 2003

4. S. Michaïlof, La France et l'Afrique: vade-mecum pour un nouveau voyage, KARTHALA Editions, 1993-p. 413

5. Kurbanov R.A. Regional'naya integratsiya v Afrike: Mezhafrikanskaya konferentsiya sotsial'nogo strakhovaniya // Pravo i politika. - 2015. - 3. - C. 319 - 326. DOI: 10.7256/1811-9018.2015.4.14689.

6. Rogov I.I. Printsip verkhovenstva konstitutsii kak klyuchevoi faktor razvitiya mezhgosudarstvennykh integratsionnykh protsessov // Zhurnal zarubezhnogo zakonodatel'stva i sravnitel'nogo pravovedeniya / Journal of foreighn legislation and comparative law. 2013. - 6. - C. $964-966$.

7. Kurbanov R.A. Struktura energeticheskogo sektora i voprosy mezhdunarodno-pravovogo regulirovaniya energetiki Severoamerikanskikh gosudarstv // Mezhdunarodnoe pravo. - 2013. - 4. - C. 201 - 228. DOI: 10.7256/2306-9899.2013.4.11026. URL: http:// www.e-notabene.ru/wl/article 11026.html

8. Kurbanov R.A. Evraziiskoe pravo: voprosy kontseptual'nogo razvitiya // Pravo i politika. - 2014. - 12. - C. 1877 - 1887. DOI: $10.7256 / 1811-9018.2014 .12 .14003$. 